\title{
Thermal Cracking Analysis during Pipe Cooling of Mass Concrete Using Particle Flow Code
}

\author{
Liang Li, ${ }^{1,2}$ Xinghong Liu, ${ }^{3}$ Vinh T. N. Dao, ${ }^{4}$ and Yonggang Cheng ${ }^{1,2}$ \\ ${ }^{1}$ School of Water Resources and Hydropower Engineering, Wuhan University, Wuhan 430072, China \\ ${ }^{2}$ State Key Laboratory of Water Resources and Hydropower Engineering Science, Wuhan University, Wuhan 430072, China \\ ${ }^{3}$ School of Civil Engineering and Architecture, Wuhan University, Wuhan 430072, China \\ ${ }^{4}$ School of Civil Engineering, The University of Queensland, Brisbane, QLD 4072, Australia
}

Correspondence should be addressed to Liang Li; liliangrun@whu.edu.cn

Received 12 November 2015; Revised 29 February 2016; Accepted 17 March 2016

Academic Editor: Antonio Riveiro

Copyright (C) 2016 Liang Li et al. This is an open access article distributed under the Creative Commons Attribution License, which permits unrestricted use, distribution, and reproduction in any medium, provided the original work is properly cited.

\begin{abstract}
Pipe cooling systems are among the potentially effective measures to control the temperature of mass concrete. However, if not properly controlled, thermal cracking in concrete, especially near water pipes, might occur, as experienced in many mass concrete structures. In this paper, a new numerical approach to simulate thermal cracking based on particle flow code is used to shed more light onto the process of thermal crack propagation and the effect of thermal cracks on thermal fields. Key details of the simulation, including the procedure of obtaining thermal and mechanical properties of particles, are presented. Importantly, a heat flow boundary based on an analytical solution is proposed and used in particle flow code in two dimensions to simulate the effect of pipe cooling. The simulation results are in good agreement with the monitored temperature data and observations on cored specimens from a real concrete gravity dam, giving confidence to the appropriateness of the adopted simulation. The simulated results also clearly demonstrate why thermal cracks occur and how they propagate, as well as the influence of such cracks on thermal fields.
\end{abstract}

\section{Introduction}

Mass concrete plays an important role in modern civil and hydropower engineering. The American Concrete Institute (ACI) [1] stipulates that artificial measures must be taken to solve the problems caused by volumetric deformation and hydration heat during mass concrete construction. Due to the large volume of mass concrete, water pipes are often embedded into concrete to help control the concrete's temperature. However, if the pipe cooling system is not controlled properly, serious problems can occur, including concrete cracking. In order to strengthen the control on the system, a series of numerical simulations has been performed [2-4]. Most current simulations on thermal fields of mass concrete are based on the finite element method $[5,6]$ and composite element method [7]. In recent few years, the heat-fluid pipe element method has been created as a better simulation method [8]. This method can reflect the effect of water flow and water temperature on thermal fields, so the distribution near water pipes can be precisely simulated. Also, with the rapid development of concrete technology, thermal cracking had also become a widely considered problem $[9,10]$. Recently, most researches in this field have focused on the investigation on thermal cracking occurring at early ages [11, 12]. Few researches have paid attention to heat-induced cracking appearing near water pipes. The effect of thermal cracks on thermal fields has also been rarely investigated.

In an effort to address the above knowledge gaps, this paper reports outcomes of an ongoing research into thermalinduced cracking near water pipes and the influence of thermal cracks on thermal fields. Although particle flow code (PFC) has been widely used to simulate mechanical behavior of rock and concrete [13-15], there are still few samples using it to solve thermal problems of concrete. Particle flow code in 2 dimensions (PFC2D) allows particles with different sizes to be used to represent aggregate and mortar, and parallel bonds can be used to simulate cement paste. However, two key problems need to be solved before PFC2D is used to simulate 


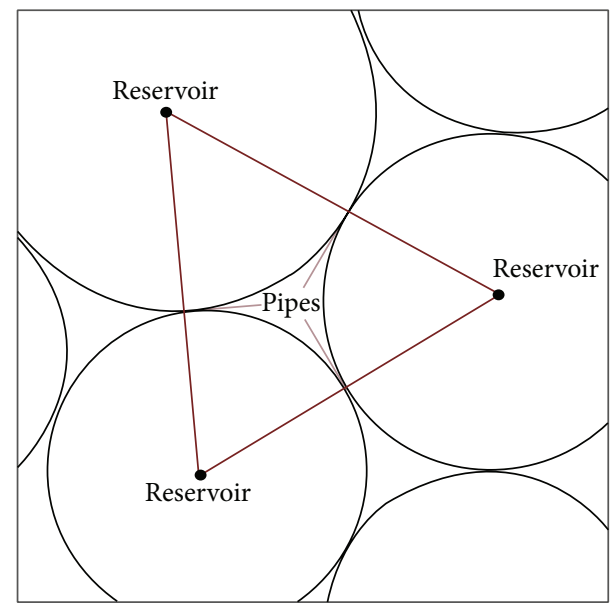

FIgURE 1: Heat conduction model.

thermal cracking induced by pipe cooling: (i) confirmation of the microparameters of concrete, including thermal and mechanical parameters, and (ii) simulation of the temperature history of pipe cooled concrete. A heat flow boundary based on an analytical solution was proposed to simulate the temperature history. The final simulation results demonstrated that the obtained heat flow boundary was available.

\section{Basic Formulation}

2.1. Heat Conduction. Before PFC is used to simulate heat conduction, the following assumptions are made to simplify simulation [16]. Firstly, concrete is simplified as a network of heat reservoirs and thermal pipes, and heat flow occurs via conduction in the active pipes that connect the reservoirs. Further, radiation of heat reservoirs and heat convection of thermal pipes are ignored. Thermal properties of particles are assumed to be temperature-independent, but thermal resistance of thermal pipes is taken into account. Each ball in Figure 1 represents a heat reservoir, and each red line symbolizes a thermal pipe. By default, a pipe is active if two particles at the contact are overlapping or a bond is present.

The governing equation of heat conduction [17] which adapts to simulate particle material is given by

$$
-\frac{\partial q_{i}}{\partial x_{i}}+q_{v}=\rho C_{v} \frac{\partial T}{\partial t}
$$

where $q_{i}$ is the heat flux vector; $q_{v}$ is the volumetric heatsource intensity; $\rho$ is the mass density; $C_{v}$ is the specific heat; $T$ is temperature; and $t$ is time.

After the concrete is discretized into a network of heat reservoirs and thermal pipes, the average value of the divergence of $q_{i}$ in the reservoir can be presented by

$$
\frac{\partial q_{i}}{\partial x_{i}}=\frac{1}{V} \sum_{p=1}^{N} Q_{p}
$$

where $Q_{p}$ is the power in pipe $p$ that is flowing out of the reservoir; $N$ is the number of thermal pipes associated with the reservoir; and $V$ is the control volume.

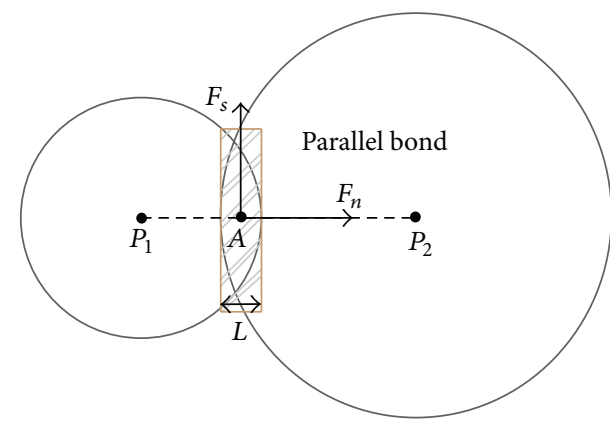

Figure 2: A parallel bond model.

The heat conduction equation for a single reservoir can be defined by substituting (2) into (1), as shown in

$$
-\sum_{p=1}^{N} Q^{(p)}+V q_{v}=m C_{v} \frac{\partial T}{\partial t},
$$

where $m$ is the thermal mass of reservoirs.

Further, thermal resistance $\eta$ is introduced into PFC2D to accurately reflect thermal microproperties of cement paste. As concrete is a thermally isotropic material, its thermal conductivity tensor can be expressed in terms of a single parameter, $k$. Assuming uniform $\eta$ for all thermal pipes, it can be written as

$$
\eta=\frac{1}{2 V k} \sum_{p=1}^{N} l^{(p)}
$$

where $V$ is the control volume and $l^{(p)}$ is the length of thermal pipes.

2.2. Parallel Bonds. To simulate the gelatination properties of cement paste, parallel bonds are used. Parallel bonds can preclude the possibility of rolling without slip and also can describe the constitutive behavior of a finite-sized piece of cementation material deposited between two balls. Generally, a parallel bond can be defined by five parameters: normal and shear stiffness, normal and shear strength, and bond radius. The main features of parallel bonds are shown in Figure 2, where the parallel bond acts on a rectangular plate, and it not only can bear tension $\left(F_{n}\right)$ and shear force $\left(F_{s}\right)$ but also can transfer moment. If bond breakages occur, thermal and mechanical properties of granular material will change immediately. In addition, all simulations in this paper are based on plane-strain conditions.

The change of each particle radius $(\Delta R)$ under a temperature change of $\Delta T$ is expressed as

$$
\Delta R=\alpha R \Delta T,
$$

where $\alpha$ is coefficient of linear thermal expansion.

Assuming that the expansion of the bond is isotropic [16, 18], the normal component of the force vector carried by the bond $\Delta \bar{F}^{n}$ will be affected by temperature change. The normal component of the bond force vector can be expressed as

$$
\Delta \bar{F}^{n}=-\bar{k}^{n} A \Delta U^{n}=-\bar{k}^{n} A(\bar{\alpha} \bar{L} \Delta T),
$$


where $\bar{k}^{n}$ is the bond normal stiffness; $A$ is the area of the bond cross section; $\bar{\alpha}$ is the expansion coefficient of the bond material; and $\bar{L}$ is the length of the bond.

\section{Engineering Background}

The concrete gravity dam to be studied is located in southwest China. Its maximum height was about 116 meters, and the volume of cast-in-place concrete was approximately $146,000 \mathrm{~m}^{3}$ per month. According to the construction technical specification (Chinese National Standard GB DL/T 5144-2001), its pipe cooling process was divided into two different phases: first stage cooling and second stage cooling. The first stage cooling occurring within the first 30 days aims at controlling the highest temperature of concrete during its early ages. The second stage cooling starts at 90 days, which is used to drop the concrete temperature to a stable temperature. Between 30 days and 90 days, no pipe cooling is carried out. A typical temperature history curve is shown in Figure 3. This theoretical curve shown in the figure is an ideal curve predefined based on construction requirements, while another line is measured by a thermometer embedded in the concrete. It can be seen from the figure that the measured temperature curve experiences a dramatic drop at the beginning of second stage cooling (from 90 days to 93 days, shown in Figure 3 as $T$ ). When a concrete specimen was drilled near the thermometer, it showed some cracks. Until now, large amounts of temperature data with similar experience at the beginning of second stage cooling were monitored. To estimate the risk of thermal cracking induced by the dramatic decline of temperature, this phenomenon was especially studied.

\section{Simulation Procedures}

4.1. PFC2D Model of Concrete. A concrete slab of 1 meter in length and 0.5 meters in width is modelled using PFC2D, as shown in Figure 4(a). The model contains 6,601 particles with radii ranging from 3 to 6 millimeters. The average porosity is about 0.16 . A particle is considered as aggregate if its radius is larger than 4.5 millimeters. Particles with radii of smaller 4.5 millimeters are regarded as part of the mortar. The influence of particle shape on the behavior of granular material was ignored and all particles were seen as balls [19].

Assuming that a water pipe is at the top border of the model, the border is seen as a heat flow boundary and the rest of the borders are set as adiabatic boundaries. In Figure 4(a), $Q$ symbolizes water flow with its direction indicated by arrows. In addition, heat flow in the $x$-direction is assumed as a constant. Parallel bonds and particles that are at the right and left borders are mechanically fixed in the $x$-direction, while parallel bonds and particles that are at the bottom border are mechanically fixed in all directions. Figure 4(b) illustrates the parallel bond network of the model.

\subsection{Confirmation of Parameters}

4.2.1. Thermal Properties. When concrete is seen as a particle material, the value of its density must be changed such that
TABLE 1: Thermal properties.

\begin{tabular}{lcc}
\hline Properties & Concrete & Particles \\
\hline Density $\left(\mathrm{kg} / \mathrm{m}^{3}\right)$ & 2250 & 2678 \\
Specific heat $\left(\mathrm{kJ} /\left(\mathrm{kg}^{\circ} \mathrm{C}\right)\right)$ & 1.05 & 1.05 \\
$\begin{array}{l}\text { Poisson's ratio } \\
\text { Coefficient of linear thermal expansion of }\end{array}$ & 0.20 & 0.20 \\
$\begin{array}{l}\text { aggregate }\left(10^{-5} /{ }^{\circ} \mathrm{C}\right) \\
\begin{array}{l}\text { Coefficient of linear thermal expansion of } \\
\text { mortar }\left(10^{-4} /{ }^{\circ} \mathrm{C}\right)\end{array}\end{array}$ & 1.21 & 1.45 \\
$\begin{array}{l}\text { Coefficient of thermal conductivity } \\
\left(\mathrm{W} /\left(\mathrm{m}^{\circ} \mathrm{C}\right)\right)\end{array}$ & 2.56 & 2.20 \\
\hline
\end{tabular}

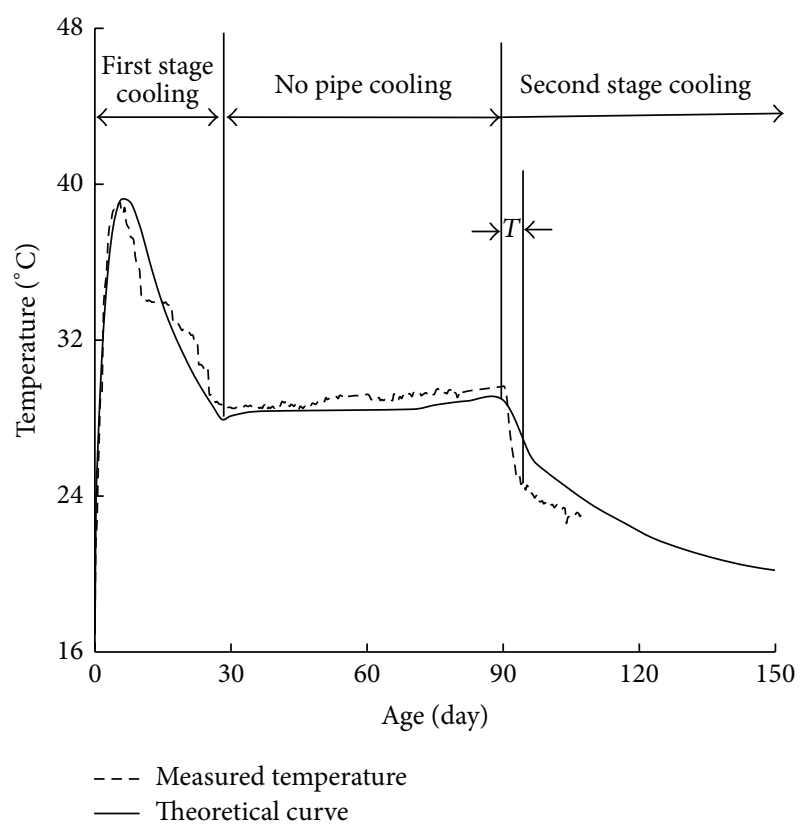

FIGURE 3: Water cooling process.

particle has the same total thermal mass as concrete. The value of density of particle can be expressed as

$$
\rho=\frac{\rho_{c}}{1-n}
$$

where $\rho_{c}$ is the density of concrete and $n$ is the average porosity of the particle.

The specific heat of particles can be set equal to the average specific heat of concrete. According to (4), thermal resistance of each pipe can be set. The coefficient of linear thermal expansion of particles is presented by

$$
\alpha=\alpha_{c}(1+v)
$$

where $\alpha_{c}$ is the coefficient of linear thermal expansion of concrete and $v$ is Poisson's ratio.

Thermal properties of concrete used in the gravity dam are summarized in Table 1 . These parameters were obtained by concrete tests in accordance with DL/T5150-2001 [20]. Based on (7) and (8), thermal properties of the particles can be obtained (see Table 1). 


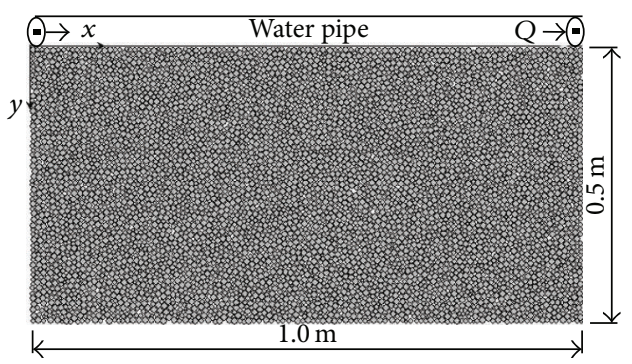

(a)

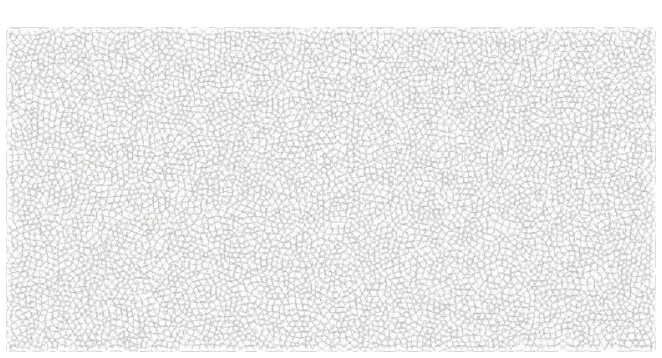

(b)

FIGURE 4: Particle model of a concrete slab: (a) position of water pipe and (b) parallel bonds network.

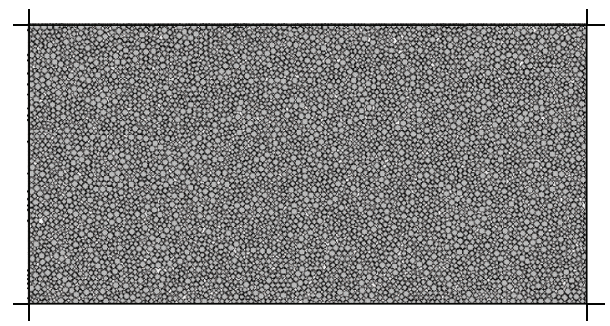

FIgURE 5: Biaxial compression test model.

4.2.2. Mechanical Properties. Unlike thermal properties of particles, mechanical properties cannot be obtained directly by concrete tests. To obtain mechanical properties of aggregate and mortar, a biaxial compression test was performed in PFC2D [21, 22]. The model shown in Figure 4 was used to simulate the test, but those constraint conditions on the model were deleted and four walls were added (see Figure 5). As shown in Figure 5, the top and bottom walls of the model are used to simulate the confinement, while the left and right walls are used to simulate loading platens. The test was loaded in a strain-controlled fashion by specifying the velocities of the left and right walls, while the velocities of the top and bottom walls were controlled automatically by a numerical servomechanism.

In the biaxial compression test, confining pressure was set at $5 \mathrm{MPa}, 10 \mathrm{MPa}, 15 \mathrm{MPa}$, and $20 \mathrm{MPa}$, respectively. Mechanical parameters of particles are listed in Table 2, and four groups of stress-strain curves were obtained (see Figure 6). In Figure 6, the strain softening behavior of concrete is simulated exactly, and stress-strain curves basically satisfy linear relationships at the beginning of loading. After peaking at maximum stress, with axial strain rising, axial stress experiences a rapid decrease. With the confining pressure rising from $5 \mathrm{MPa}$ to $20 \mathrm{MPa}$, the value of the highest axial stress also experiences an increase by about 16.7 MPa.

\subsection{Boundary and Initial Conditions}

4.3.1. Heat Flow Boundary. To simulate the temperature history of concrete with pipe cooling, a heat flow boundary was presented and used in PFC2D. The governing equation of heat conduction which adapts to simulate the concrete slab
TABLE 2: Mechanical properties of particles.

\begin{tabular}{llc}
\hline Properties & Mechanical microproperties & Value \\
\hline $\begin{array}{l}\text { Microproperties of } \\
\text { aggregate and mortar }\end{array}$ & Normal stiffness $\left(\times 10^{9} \mathrm{~N} / \mathrm{m}\right)$ & 50 \\
& Shear stiffness $\left(\times 10^{9} \mathrm{~N} / \mathrm{m}\right)$ & 50 \\
& Friction coefficient & 0.25 \\
\hline & Normal stiffness $\left(\times 10^{9} \mathrm{~N} / \mathrm{m}\right)$ & 20 \\
$\begin{array}{l}\text { Microproperties of the } \\
\text { interface between } \\
\text { mortar and mortar }\end{array}$ & $\begin{array}{l}\text { Shear stiffness }\left(\times 10^{9} \mathrm{~N} / \mathrm{m}\right) \\
\left(\times 10^{6} \mathrm{~N}\right)\end{array}$ & 20 \\
& Shear bond strength $\left(\times 10^{6} \mathrm{~N}\right)$ & 10 \\
\hline & $\begin{array}{l}\text { Normal stiffness }\left(\times 10^{9} \mathrm{~N} / \mathrm{m}\right) \\
\text { Microproperties of the }\end{array}$ & 30 \\
Shear stiffness $\left(\times 10^{9} \mathrm{~N} / \mathrm{m}\right)$ & 30 \\
aggregate and mortar & $\begin{array}{l}\text { Normal bond strength } \\
\left(\times 10^{6} \mathrm{~N}\right)\end{array}$ & 4 \\
& Shear bond strength $\left(\times 10^{6} \mathrm{~N}\right)$ & 10 \\
\hline
\end{tabular}

can be expressed as (9), and (10) represents initial boundary conditions [23]. Consider the following:

$$
\begin{aligned}
\frac{\partial T}{\partial \tau} & =a\left(\frac{\partial^{2} T}{\partial y^{2}}+\frac{1}{y} \frac{\partial T}{\partial y}\right) \\
-\lambda_{c} \frac{\partial T}{\partial y}+\frac{\lambda\left(T-T_{w}\right)}{r_{1} \ln \left(r_{1} / r_{0}\right)} & =0 \quad(\tau>0, y=0) \\
\frac{\partial T}{\partial y} & =0 \quad\left(\tau>0, y=r_{c}\right) \\
T(y, 0) & =T_{c} \quad\left(\tau=0,0<y \leq r_{c}\right),
\end{aligned}
$$

where $\tau$ is the age of concrete; $a$ is the thermal diffusivity of concrete; $T_{c}$ is the initial temperature of the concrete slab; $T_{w}$ is the temperature of cooling water; $\lambda_{c}$ and $\lambda$ are the coefficients of thermal conductivity of concrete and water pipes; $r_{1}$ and $r_{0}$ are the outer and inner radius of water pipe; and $r_{c}$ is the width of the concrete slab in $y$-direction.

The approximate analytical solution of average temperature of the concrete slab can be expressed as

$$
T=T_{w}+\left(T_{c}-T_{w}\right) e^{-s^{2} a \tau / r_{c}^{2}}
$$

where $s$ is an eigenvalue which is closely related to $r_{c}, \lambda, r_{1}$, and $r_{0}$. In the paper, $s$ is set as 0.71 . 


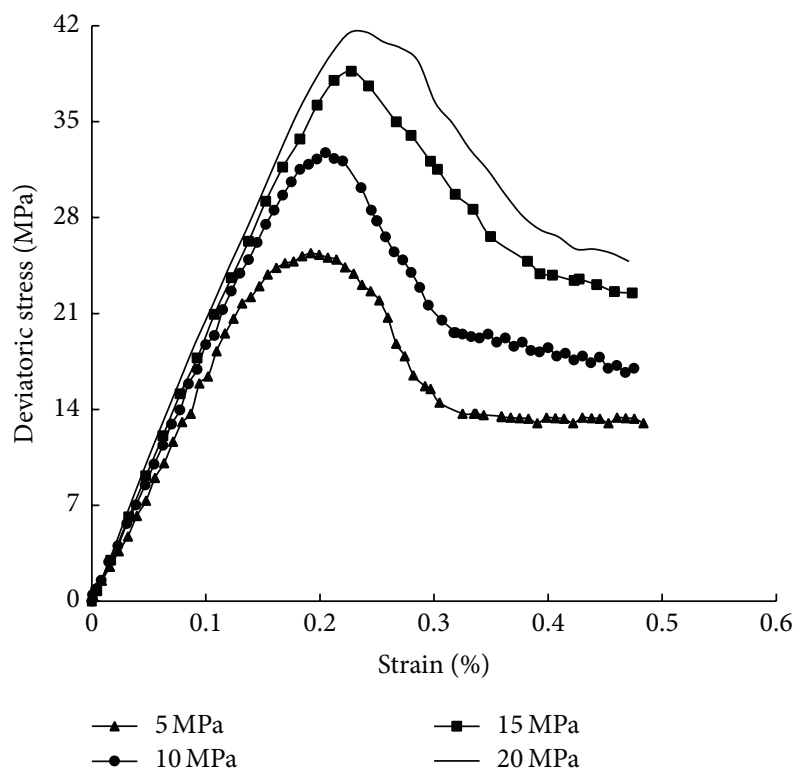

FiguRE 6: Stress-strain curves of biaxial compression tests.

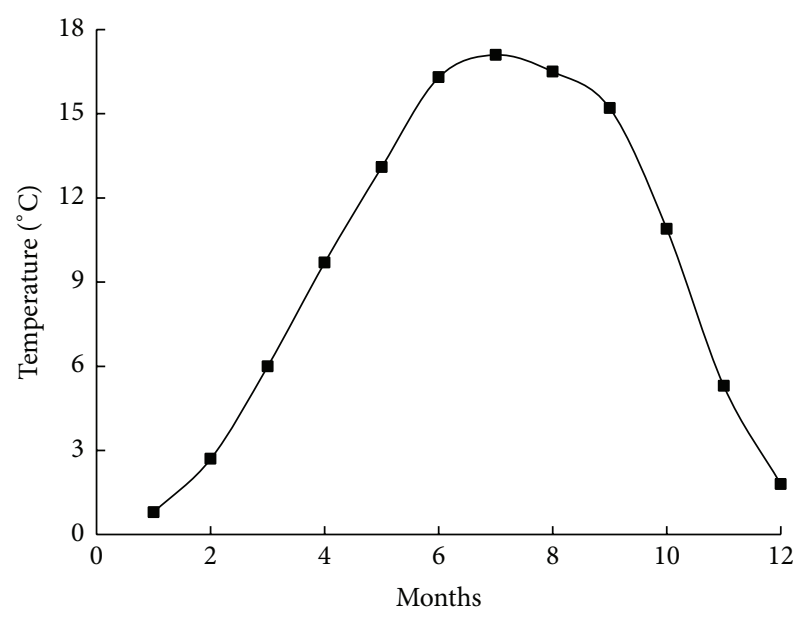

FIGURE 7: Annual average temperature variation of river water.

Based on (10) and (11), the heat flow boundary on the top border can be approximately defined as

$$
q=\lambda_{c} \frac{\partial T}{\partial y}=\frac{\lambda\left(T_{c}-T_{w}\right)}{r_{1} \ln \left(r_{1} / r_{0}\right)} e^{-s^{2} a \tau / r_{c}{ }^{2}}
$$

4.3.2. Initial Conditions. During the construction of the concrete gravity dam, river water was often used directly as cooling water. The annual average temperature variation of river water in the construction site is shown in Figure 7. The average temperature of river water is about $2^{\circ} \mathrm{C}$ in winter, $10^{\circ} \mathrm{C}$ in autumn, $14^{\circ} \mathrm{C}$ in spring, and $18^{\circ} \mathrm{C}$ in summer. So, four typical pipe cooling cases were studied particularly to estimate the probability of thermal cracks appearing at the beginning of the second stage cooling. Initial conditions of the four cases are listed in Table 3. Initial temperature of the particle slab was set as $30^{\circ} \mathrm{C}$, and the cooling water temperature was set as
TABLE 3: Initial conditions.

\begin{tabular}{lcccc}
\hline Item & $\begin{array}{c}\text { Case 1 } \\
\text { Winter }\end{array}$ & $\begin{array}{c}\text { Case 2 } \\
\text { Autumn }\end{array}$ & $\begin{array}{c}\text { Case 3 } \\
\text { Spring }\end{array}$ & $\begin{array}{c}\text { Case 4 } \\
\text { Summer }\end{array}$ \\
\hline $\begin{array}{l}\text { Concrete initial } \\
\text { temperature } /{ }^{\circ} \mathrm{C}\end{array}$ & 30 & 30 & 30 & 30 \\
$\begin{array}{l}\text { Cooling water } \\
\text { temperature } /\end{array}$ & 2 & 10 & 14 & 18 \\
$\begin{array}{l}\text { Temperature } \\
\text { difference } /\end{array}$ & $28 \mathrm{C}$ & 20 & 16 & 12 \\
\hline
\end{tabular}

the average temperature of river water. The outer radius of the high density polyethylene plastic pipe (HDPE) used in the dam was 0.016 meters, with inner radius of 0.014 meters. Thermal conductivity coefficient of the pipe was about $0.461 \mathrm{~W} /\left(\mathrm{m}^{\circ} \mathrm{C}\right)$. The average temperature variation of the slab was then calculated. Using (11), The results of the temperature variation of the slab calculated by (11) are presented in Figure 8(a). It demonstrates that the lower the temperature of cooling water, the faster the cooling rate of the slab. By substituting the results of average temperature into (12), the average heat flow variation on the top border was calculated (see Figure $8(\mathrm{~b})$ ) and used to simulate the effect of pipe cooling in PFC2D.

\section{Results and Discussion}

5.1. Thermal Results Analysis. To conveniently analyze the simulated thermal field, the slab was artificially divided into 10 equal slices along the $y$-axis, and the average temperature of the particles within each slice was computed. After 72 hours of pipe cooling, thermal gradients along the $y$-direction are shown in Figure 9, with the horizontal axis representing the distance from slices to the top border. As expected, it can be seen that the lower the cooling water temperature, the higher the thermal gradient. Average temperature history of the bottom slice with a distance of about 0.5 meters from the top border is shown in Figure 10, and the simulation results are used to compare it with the monitored temperature. Tt10102, Tt17-74, Tt13-67, and Tt11-109 are labels of thermometers embedded in the concrete, and the distance between thermometers and water pipes is about 0.5 meters (see Figure 10). In all four cases, second stage cooling started at 90 days, and the simulation ended at 93 days. There appears a very strong agreement between the simulated results and the measured temperatures, indicating that thermal properties of particles and boundary conditions used in the simulation were appropriate.

5.2. Thermal Crack Propagation. Thermal cracking states of the slab after 72 hours of pipe cooling are shown in Figure 11. In Case 1 (see Figure 11(a)), a long thermal crack of about 0.5 meters in length runs through the middle of the slab, besides a somewhat random network of tiny thermal cracks near the top border. In Case 2, a shorter thermal crack of an approximate 390 millimetres in length occurs also near the middle of the slab (see Figure 11(b)), but there is no network of tiny thermal cracks adjacent to the top border as in Case 1. 


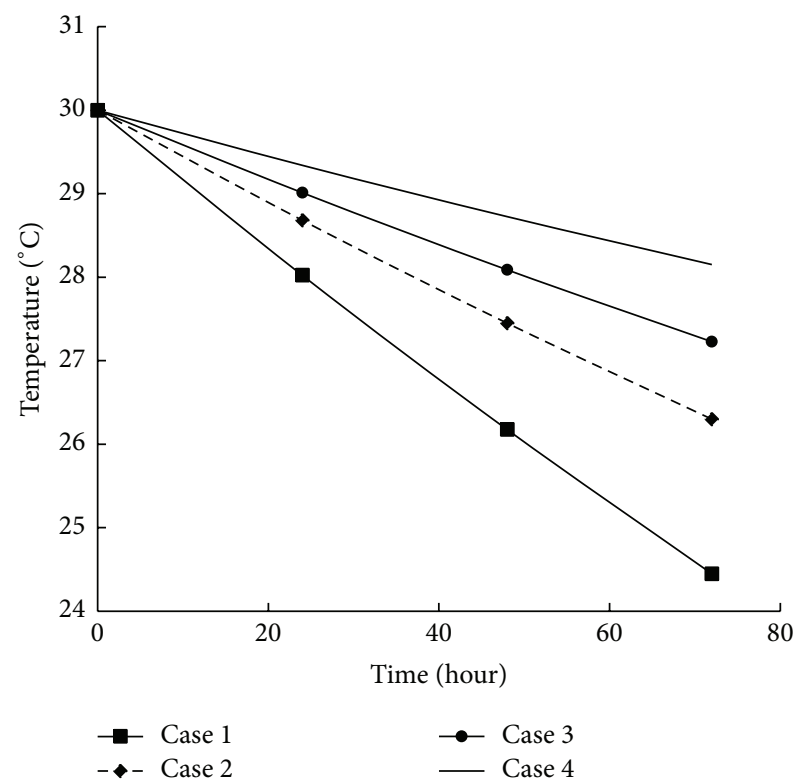

(a)

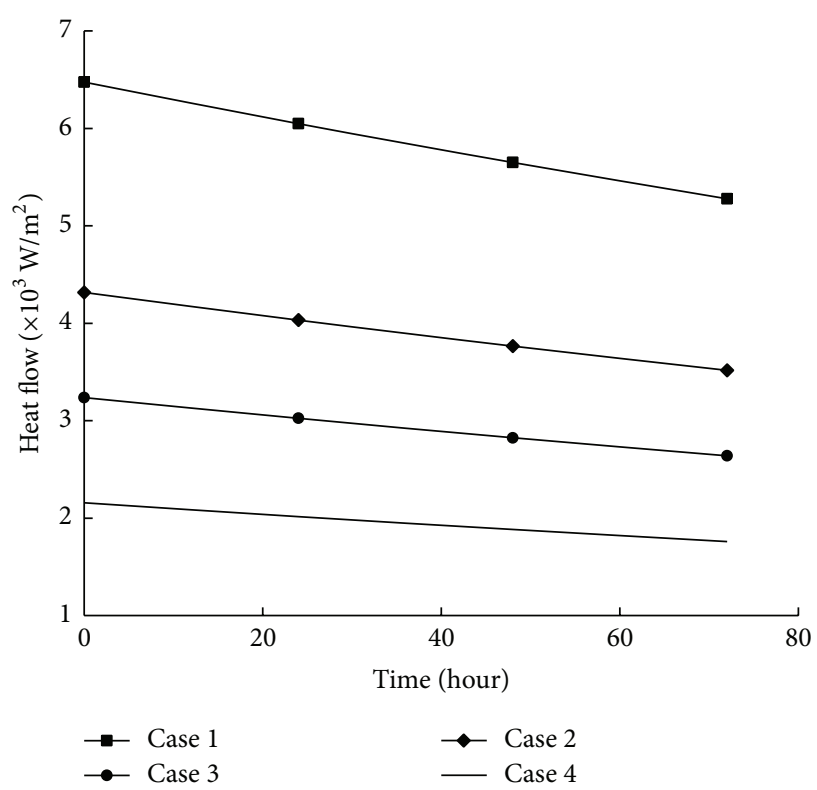

(b)

FIGURE 8: Initial conditions: (a) average temperature variation and (b) average heat flow variation.

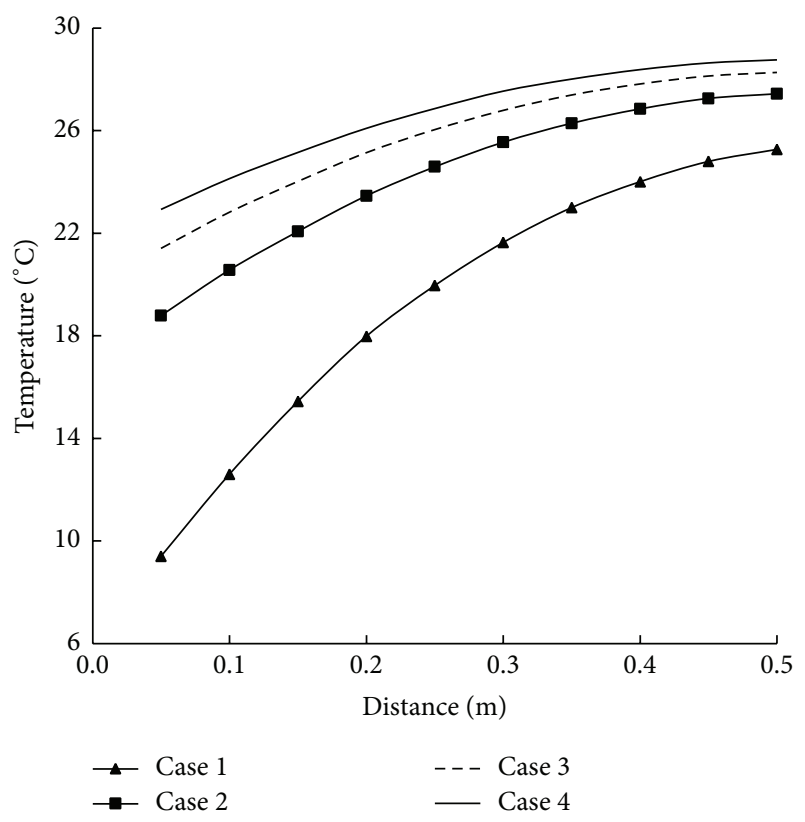

Figure 9: Thermal gradient of the particle slab.

In Case 3 (see Figure 11(c)), the dominant thermal crack in the middle region is about 140 millimeters long. In Figure 11(d), no thermal crack is predicted in Case 4 .

Such simulated cracking appears to agree very well with concrete cores taken from the dam at locations near the mentioned thermometers (Tt10-102, Tt17-74, Tt13-67, and Tt11109). Figure 12(a) clearly shows that there is a long thermal crack in the concrete specimen drilled near Tt10-102 thermometer, which is in accordance with the simulation results shown in Figure 11(a). In Figures 12(b) and 12(c), thermal cracks as observed in cored specimens are also highly consistent with simulated cracking in corresponding cases. The specimen drilled near Tt11-109 thermometer showed no thermal cracks (Figure 12(d)), which is again in good agreement with the simulation in Case 4. Overall, a few tiny cracks appear firstly near water pipes. Then, one of tiny heat-induced cracks propagates rapidly, which explains why only one long crack is found in each concrete specimen. After the crack reaches a certain length and gradually stops propagating, more tiny thermal cracks appear near the water pipe. To sum up, it can be concluded that the lower the temperature difference between concrete and cooling water, the lower the cracking risk. When the temperature of the river gets too low, some heating of such water may be required before using it as cooling water.

5.3. Effect of Thermal Cracks on Thermal Fields. Thermal fields of the slab after 72 hours of pipe cooling are shown in Figure 13. The temperature of each particle is drawn as a filled red circle located at the particle center, with a radius proportional to magnitude. Figure 13(a) shows that thermal field, having been modified by the presence if the network of thermal cracking, becomes nonuniform and unsymmetrical. Generally, a thermal pipe is active if two particles at the contact are overlapping or if a bond is present. Once bond breakages occur, it modifies the number of active thermal pipes and changes its ability to conduct heat. This explains why thermal distribution in Case 1 becomes nonuniform and discontinuous. Additionally, the temperature near the top border is about $9.40^{\circ} \mathrm{C}$, while the temperature near the bottom border is about $25.21^{\circ} \mathrm{C}$. Figure $13(\mathrm{~b})$ demonstrates that thermal distribution in Case 2 is basically horizontal and uniform, and the temperature near the top and bottom borders is $18.69^{\circ} \mathrm{C}$ and $27.34^{\circ} \mathrm{C}$, respectively. In the positions 


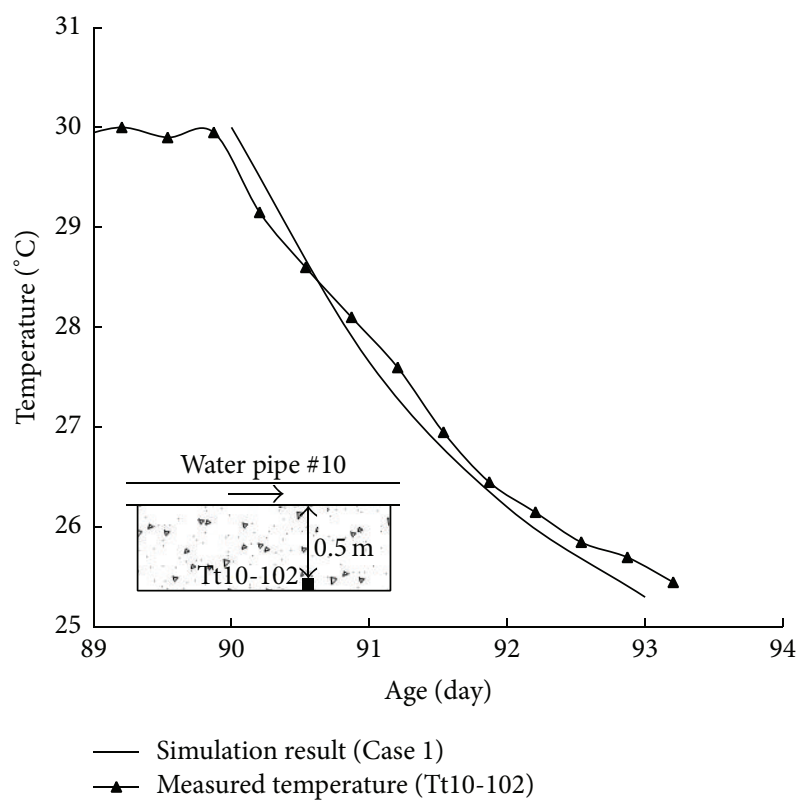

(a)

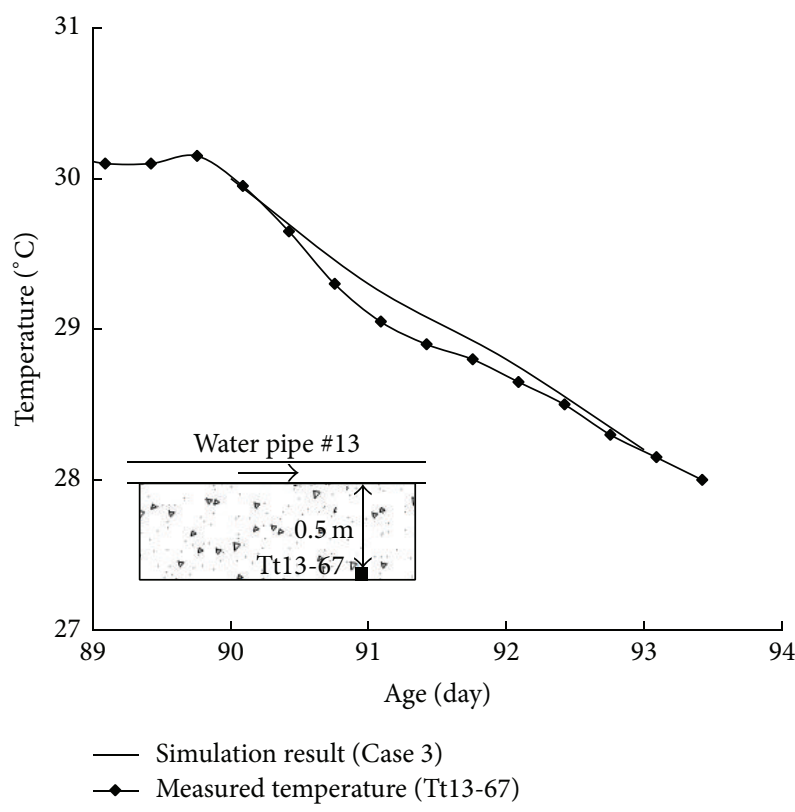

(c)

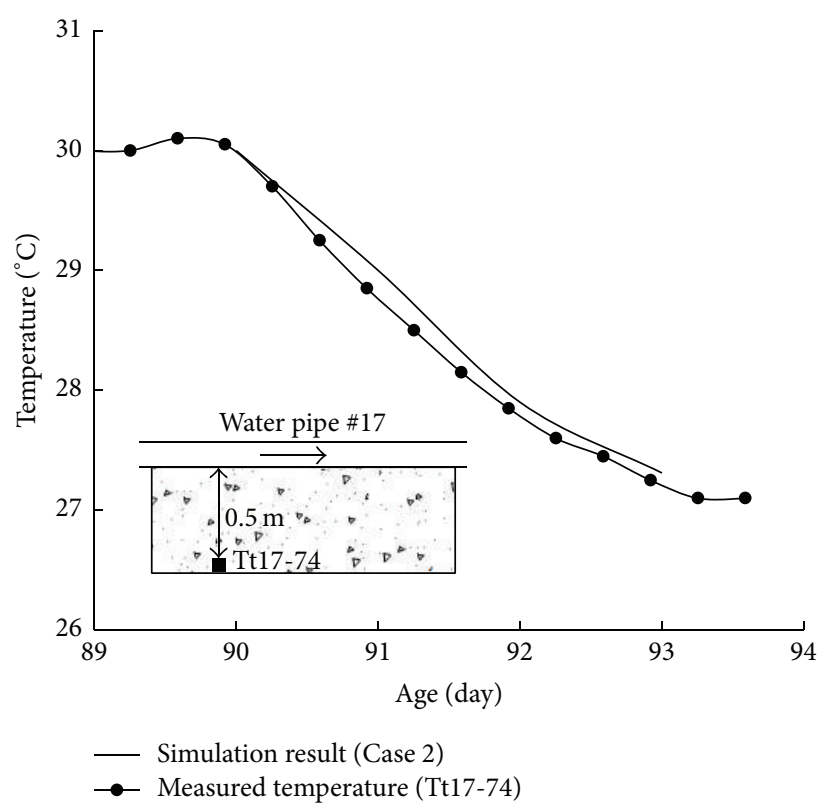

(b)

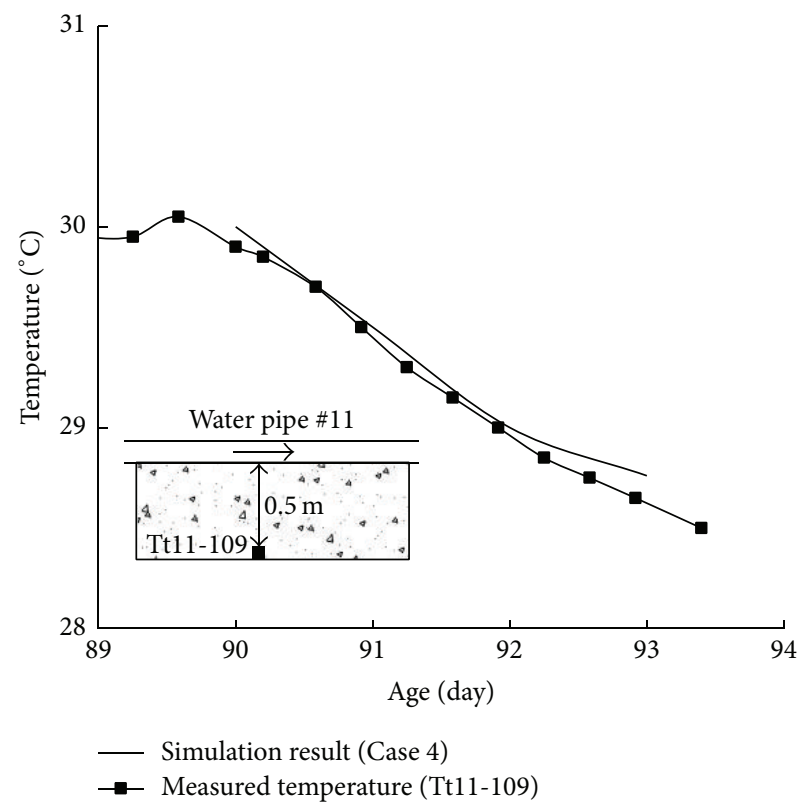

(d)

Figure 10: Temperature history of the bottom slice: (a) Case 1, (b) Case 2, (c) Case 3, and (d) Case 4.

of $C_{1}$ and $C_{2}$, the distribution is obviously influenced by thermal cracking and thermal field becomes discontinuous and unsymmetrical. Compared with Cases 1 and 2, the small thermal crack shown in the position of $C_{3}$ (see Figure 13(c)) has little influence on the thermal field. In Case 4 (see Figure 13(d)), no thermal crack appears in the slab, and the thermal field is horizontal and uniform.

\section{Conclusions}

According to the above simulation results, the following conclusions can be drawn:
(1) The new numerical method presented in the paper based on PFC2D is sufficiently rigorous to simulate crack propagation in concrete slabs, with the heat flow boundary conditions used to simulate the effect of pipe cooling proven appropriate. The simulation results, which agree well with observations on specimens cored from a real dame structure, clearly show the thermal crack propagation as well as the influence of such thermal cracks on thermal fields.

(2) Concrete cracks might occur, if the cooling water temperature is too low or the large temperature difference 


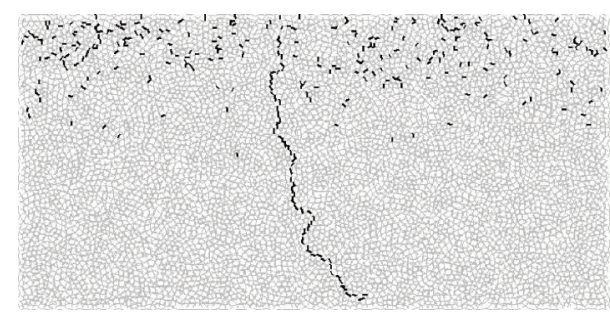

(a)

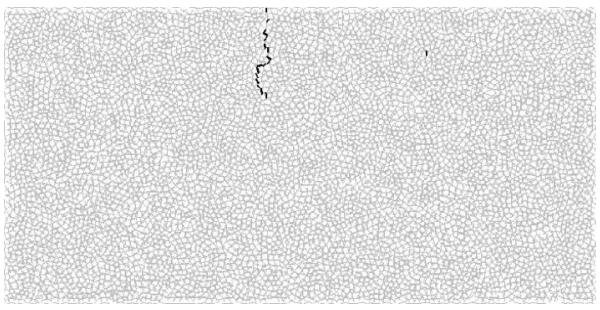

(c)

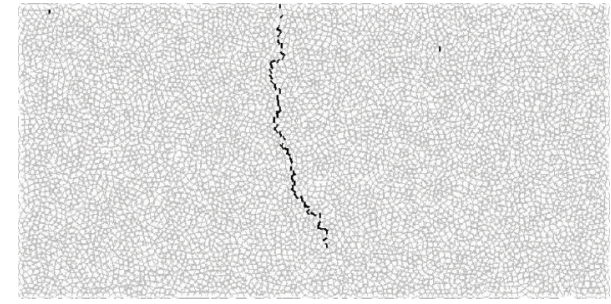

(b)

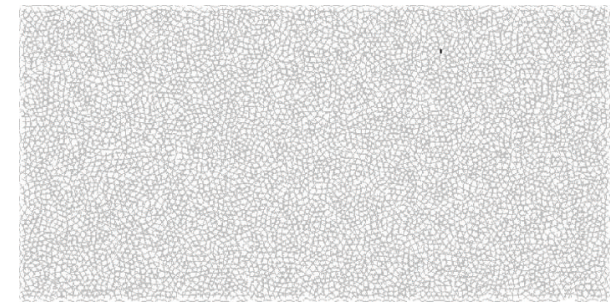

(d)

FIgUre 11: Thermal cracking states of the slab: (a) Case 1, (b) Case 2, (c) Case 3, and (d) Case 4.

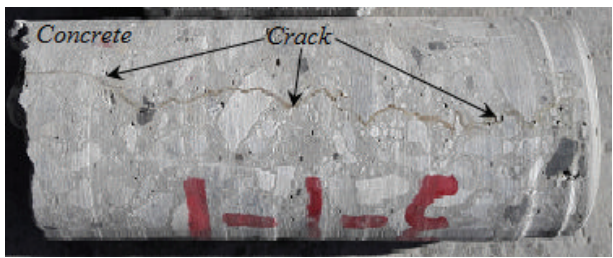

(a)

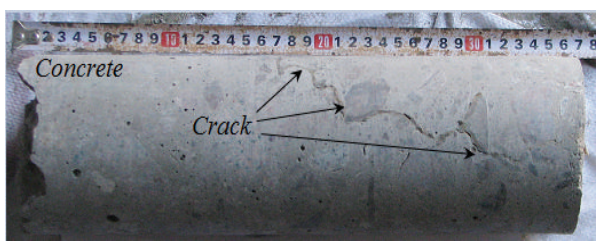

(c)

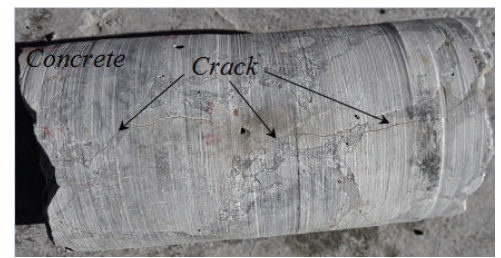

(b)

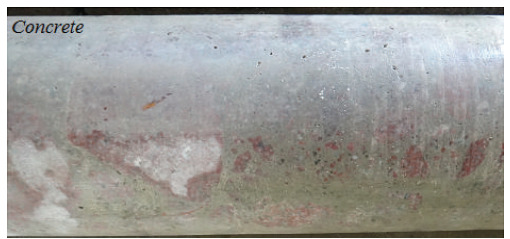

(d)

FIgURE 12: Concrete specimens: (a) Tt10-102, (b) Tt17-74, (c) Tt13-67, and (d) Tt11-109.

between concrete and cooling water is too high. To reduce the risk of thermal cracking, the temperature difference should be controlled.

(3) When thermal cracks occur, corresponding bond breakages also occur. Thermal fields affected by the occurrence of thermal cracks become nonuniform and discontinuous, which might subsequently compromise the safety of mass concrete.

\section{Notations}

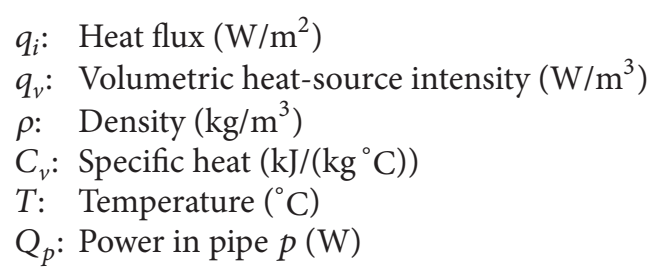

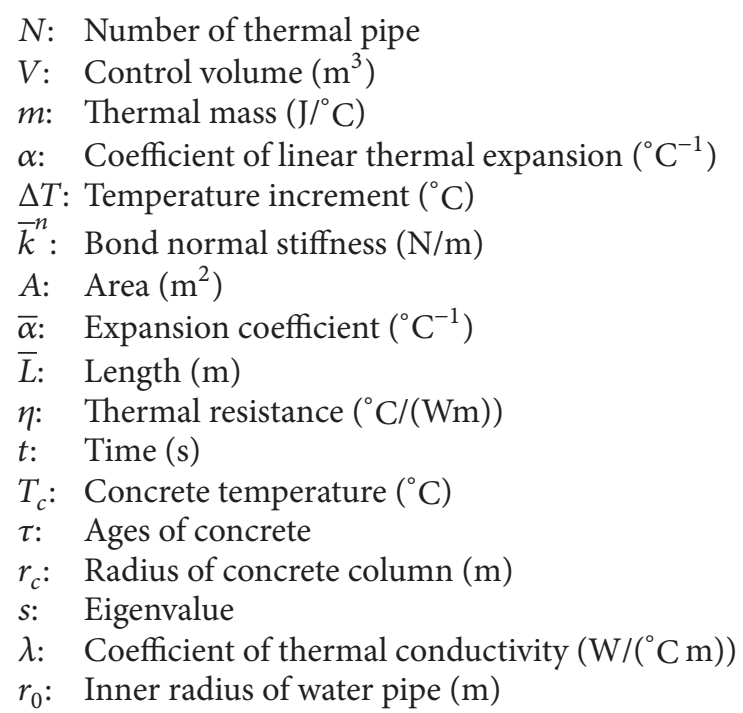




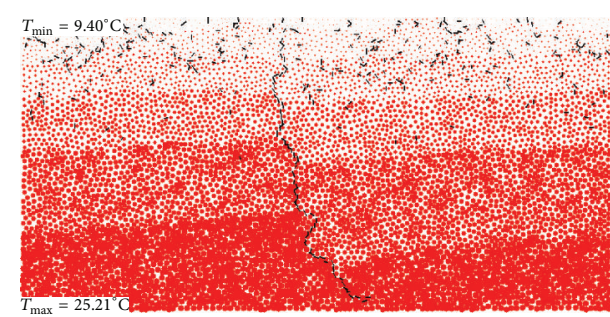

(a)

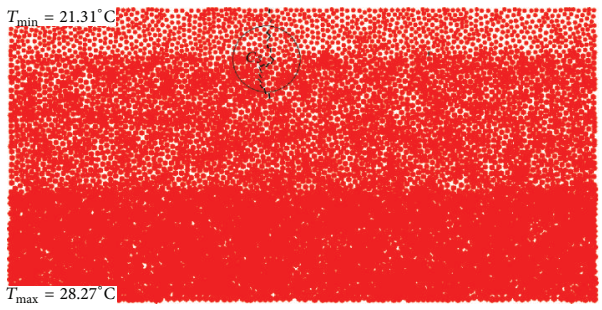

(c)

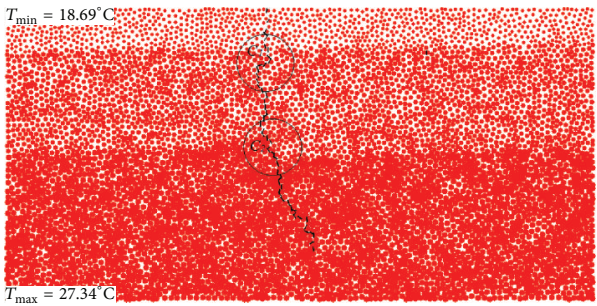

(b)

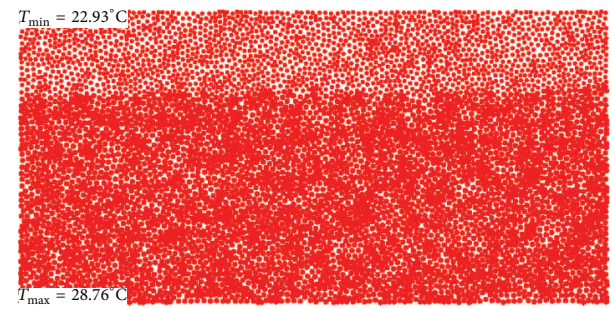

(d)

FIGURE 13: Influence of thermal cracks on thermal fields: (a) Case 1, (b) Case 2, (c) Case 3, and (d) Case 4.

$r_{1}$ : Outer radius of water pipe $(\mathrm{m})$

$v$ : Poisson's ratio

$k$ : Thermal conductivity tensor $\left(\mathrm{W} /\left({ }^{\circ} \mathrm{C} \mathrm{m}\right)\right)$

$R$ : Particle radius $(\mathrm{m})$

$n$ : Porosity.

\section{Subscripts}

c: Concrete

$w$ : Water

p: Thermal pipes.

\section{Abbreviations}

PFC: $\quad$ Particle flow code

PFC2D: Particle flow code in 2 dimensions

HDPE: High density polyethylene plastic pipe.

\section{Competing Interests}

The authors declare that they have no competing interests.

\section{Acknowledgments}

The authors gratefully acknowledge financial support from the National Science Fund for Distinguished Young Scholars of China (no. 51322905), the National Basic Research Program of China (973 Program, no. 2013BC0359001), and the China Scholarship Council.

\section{References}

[1] ACI Committee, Building Code Requirements for Structural Concrete and Commentary, American Concrete Institute, Farmington Hills, Mich, USA, 2005.

[2] A. Gaspar, F. Lopez-Caballero, A. Modaressi-FarahmandRazavi, and A. Gomes-Correia, "Methodology for a probabilistic analysis of an RCC gravity dam construction. Modelling of temperature, hydration degree and ageing degree fields," Engineering Structures, vol. 65, pp. 99-110, 2014.

[3] Z. Yunchuan, B. Liang, Y. Shengyuan, and C. Guting, "Simulation analysis of mass concrete temperature field," Procedia Earth and Planetary Science, vol. 5, pp. 5-12, 2012.

[4] A. C. de Nailde, J. P. Lineu, and J. Henrique, "Use of ANSYS for thermal analysis in mass concrete," Journal of Civil Engineering and Architecture, vol. 8, no. 7, pp. 860-868, 2014.

[5] S. Chen, P. Su, and I. Shahrour, "Composite element algorithm for the thermal analysis of mass concrete," International Journal of Numerical Methods for Heat \& Fluid Flow, vol. 21, no. 4, pp. 434-447, 2011.

[6] D. Santillán, E. Salete, and M. Á. Toledo, "A new 1D analytical model for computing the thermal field of concrete dams due to the environmental actions," Applied Thermal Engineering, vol. 85, pp. 160-171, 2015.

[7] J. X. Ding and S. H. Chen, "Simulation and feedback analysis of the temperature field in massive concrete structures containing cooling pipes," Applied Thermal Engineering, vol. 61, no. 2, pp. 554-562, 2013

[8] X. Liu, C. Zhang, X. Chang, W. Zhou, Y. Cheng, and Y. Duan, "Precise simulation analysis of the thermal field in mass concrete with a pipe water cooling system," Applied Thermal Engineering, vol. 78, no. 5, pp. 449-459, 2015.

[9] M. Azenha, R. Lameiras, C. de Sousa, and J. Barros, "Application of air cooled pipes for reduction of early age cracking risk in a massive RC wall," Engineering Structures, vol. 62-63, no. 2, pp. 148-163, 2014.

[10] J.-H. Ha, Y. S. Jung, and Y.-G. Cho, "Thermal crack control in mass concrete structure using an automated curing system," Automation in Construction, vol. 45, pp. 16-24, 2014.

[11] N. Shi, J. Ouyang, R. Zhang, and D. Huang, "Experimental study on early-age crack of mass concrete under the controlled temperature history," Advances in Materials Science and Engineering, vol. 2014, Article ID 671795, 10 pages, 2014.

[12] V. T. N. Dao, P. H. Morris, and P. F. Dux, "Crack propagation in concrete at very early ages," Magazine of Concrete Research, vol. 66, no. 13, pp. 643-651, 2014. 
[13] D. Markauskas and R. Kačianauskas, "Compacting of particles for biaxial compression test by the discrete element method," Journal of Civil Engineering and Management, vol. 12, no. 2, pp. 153-161, 2006.

[14] L. Scholtès and F.-V. Donzé, "Modelling progressive failure in fractured rock masses using a 3D discrete element method," International Journal of Rock Mechanics \& Mining Sciences, vol. 52, pp. 18-30, 2012.

[15] X.-P. Zhang and L. N. Y. Wong, "Cracking processes in rock-like material containing a single flaw under uniaxial compression: a numerical study based on parallel bonded-particle model approach," Rock Mechanics and Rock Engineering, vol. 45, no. 5, pp. 711-737, 2012.

[16] Itasca Consulting Group, PFC2D Manual Version 3.0, Itasca Consulting Group, Minneapolis, Minn, USA, 2002.

[17] H. S. Carslaw and J. C. Jaeger, Conduction of Heat in Solids, Oxford Press, London, UK, 2nd edition, 1959.

[18] Y. Shimizu, R. Hart, and P. Cundall, "Numerical modeling in micromechanics via particle methods," in Proceedings of the 2nd International PFC Symposium, Kyoto, Japan, October 2004.

[19] S. A. A. M. Fennis and J. C. Walraven, "Using particle packing technology for sustainable concrete mixture design," Heron, vol. 57, no. 2, pp. 73-101, 2012.

[20] China Institute of Water Resources and Hydropower Research, Test Code for Hydraulic Concrete, China Standards Press, Beijing, China, 2001.

[21] J. Yoon, "Application of experimental design and optimization to PFC model calibration in uniaxial compression simulation," International Journal of Rock Mechanics \& Mining Sciences, vol. 44, no. 6, pp. 871-889, 2007.

[22] C. M. López, I. Carol, and A. Aguado, "Meso-structural study of concrete fracture using interface elements. II: compression, biaxial and Brazilian test," Materials and Structures/Materiaux et Constructions, vol. 41, no. 3, pp. 601-620, 2008.

[23] B. F. Zhu, Thermal Stress and Temperature Control in Mass Concrete, China Electric Power Press, Beijing, China, 2012. 

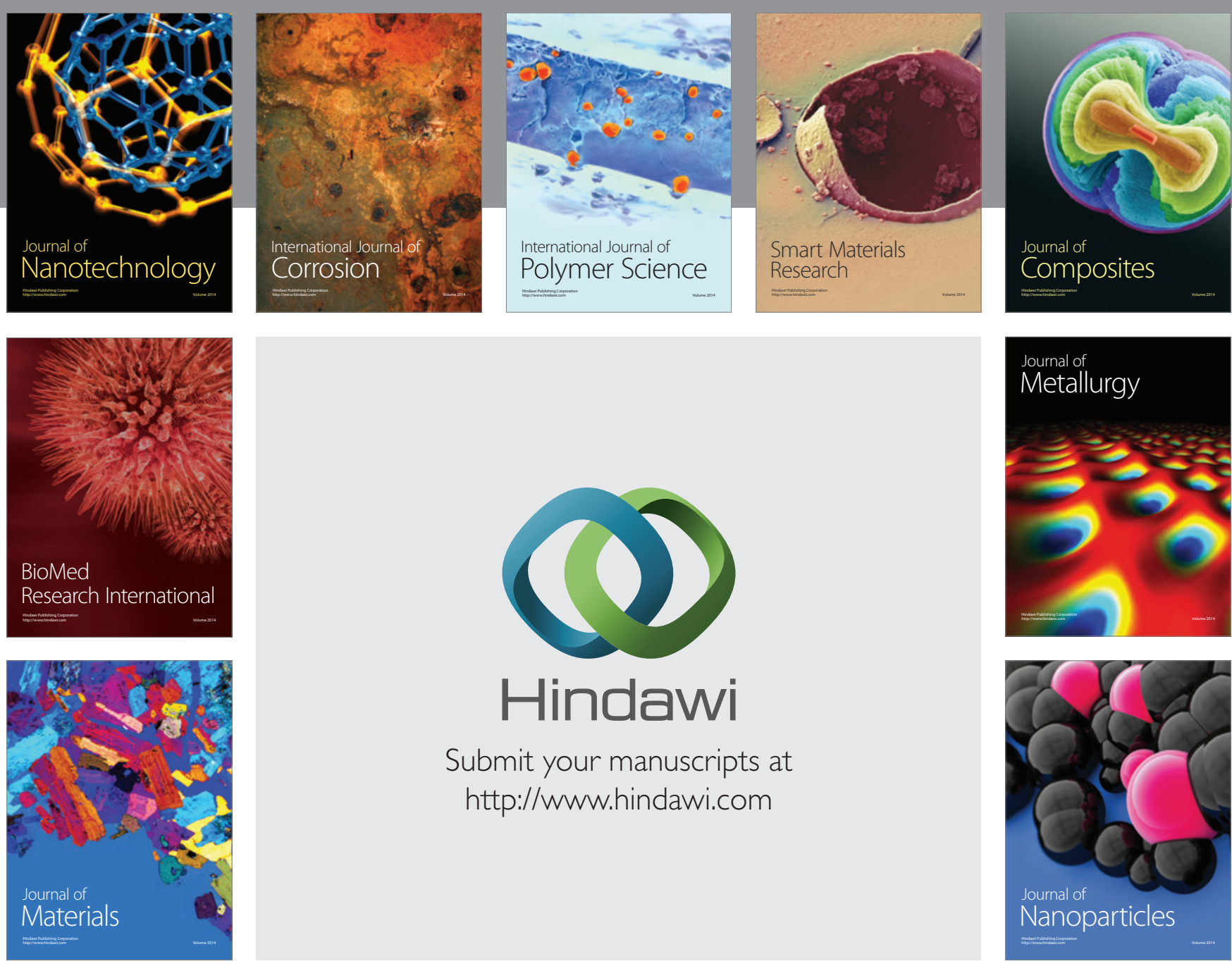

\section{Hindawi}

Submit your manuscripts at

http://www.hindawi.com

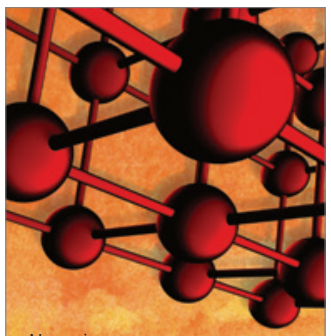

Materials Science and Engineering
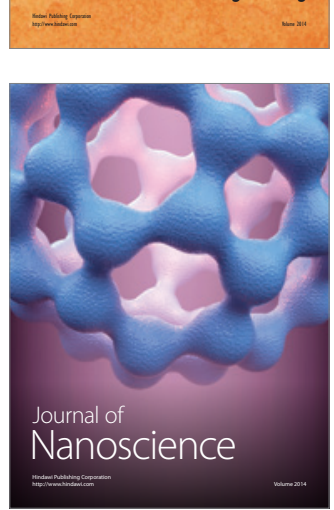
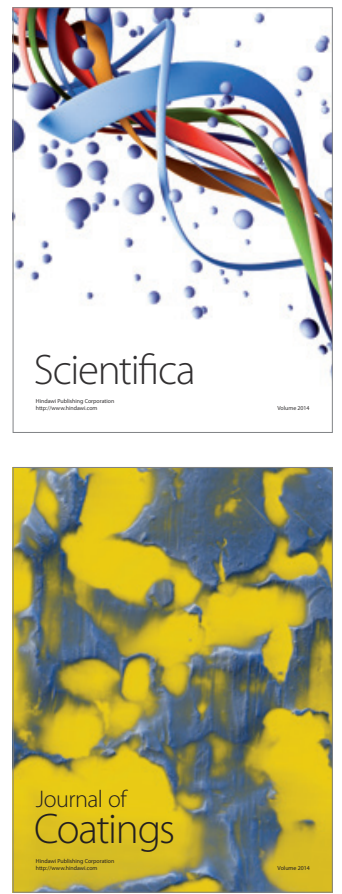
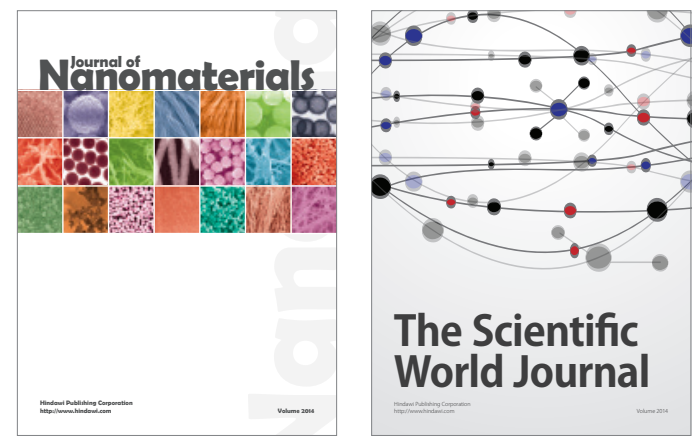

The Scientific World Journal
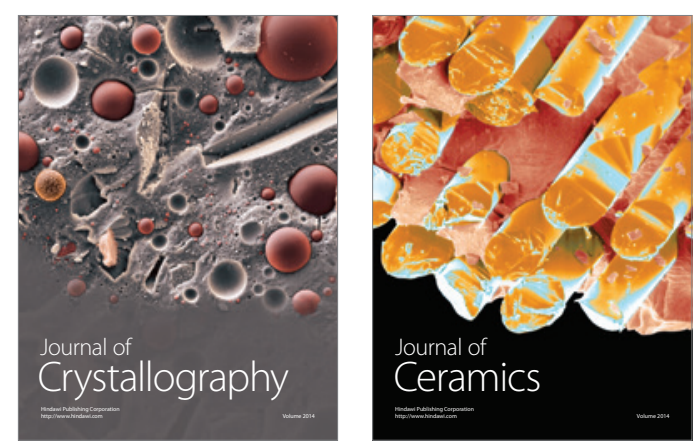
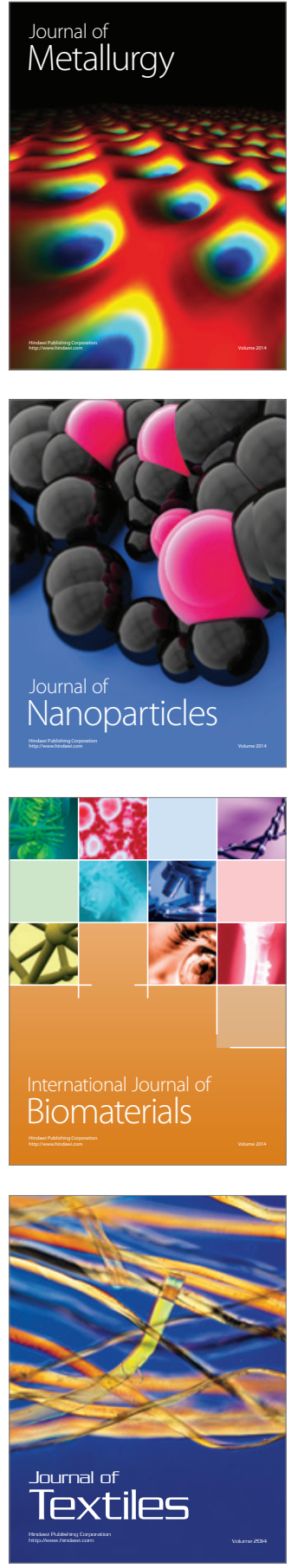